\title{
An 8-gene qRT-PCR-based gene expression score that has prognostic value in early breast cancer
}

\author{
Iker Sánchez-Navarro+1, Angelo Gámez-Pozo+1, Álvaro Pinto², David Hardisson³, Rosario Madero4 ${ }^{4}$ Rocío López', \\ Belén San José ${ }^{4}$, Pilar Zamora², Andrés Redondo², Jaime Feliu², Paloma Cejas', Manuel González Barón2,5, Juan Ángel \\ Fresno Vara*1 and Enrique Espinosa*2
}

\begin{abstract}
Background: Gene expression profiling may improve prognostic accuracy in patients with early breast cancer. Our objective was to demonstrate that it is possible to develop a simple molecular signature to predict distant relapse.

Methods: We included 153 patients with stage I-II hormonal receptor-positive breast cancer. RNA was isolated from formalin-fixed paraffin-embedded samples and QRT-PCR amplification of 83 genes was performed with gene expression assays. The genes we analyzed were those included in the 70-Gene Signature, the Recurrence Score and the Two-Gene Index. The association among gene expression, clinical variables and distant metastasis-free survival was analyzed using Cox regression models.

Results: An 8-gene prognostic score was defined. Distant metastasis-free survival at 5 years was 97\% for patients defined as low-risk by the prognostic score versus $60 \%$ for patients defined as high-risk. The 8 -gene score remained a significant factor in multivariate analysis and its performance was similar to that of two validated gene profiles: the 70Gene Signature and the Recurrence Score. The validity of the signature was verified in independent cohorts obtained from the GEO database.
\end{abstract}

Conclusions: This study identifies a simple gene expression score that complements histopathological prognostic factors in breast cancer, and can be determined in paraffin-embedded samples.

\section{Background}

A key aspect of the management of women with early breast cancer is the selection of adjuvant therapy, which is guided by the use of prognostic factors included in the guidelines[1,2]. However, the use of these criteria leads to unnecessary treatment in many women. Gene expression profiles may improve prognostic and predictive information in breast cancer patients, so that adjuvant chemotherapy is given only to those with the higher risk. A number of such profiles are currently available and two of them, the 70-Gene Signature (MammaPrint ${ }^{\mathrm{m}}$ ) and the Recurrence Score $\left(\right.$ OncoType $\left.^{\mathrm{mm}}\right)$ are being evaluated in phase III studies $[3,4]$.

\footnotetext{
*Correspondence: jafresno@gmail.com, eespinosa00@terra.es

1 Unidad de Investigación, Instituto de Investigación Sanitaria IdIPAZ, Hospital Universitario La Paz (Paseo de la Castellana, 261), Madrid (28046), Spain 2 Service of Oncology, IdIPAZ, Hospital Universitario La Paz (Paseo de la Castellana, 261), Madrid (28046), Spain

+ Contributed equally

Full list of author information is available at the end of the article
}

The major drawbacks to the widespread use of gene expression profiling include reservations regarding their cost/effectiveness ratio and their lack of widespread availability. For some profiles, the need for fresh-frozen biological samples adds to these drawbacks. We have previously demonstrated that 1) quantitative reversetranscriptase polymerase chain reaction (qRT-PCR) can be used to assess the genes included in the 70-Gene Signature and 2) commercially available probes can be used on formalin-fixed, paraffin-embedded (FFPE) samples to determine the 70-Gene Signature, the Recurrence Score and the Two-Gene Ratio [5,6].

In the present study, we sought to identify a gene expression profile based on the genes included in the 70Gene Signature, the Recurrence Score and the Two-Gene Ratio. Our hypotheses were as follows: 1) commercially available assays can be used to quantify gene expression by qRT-PCR using RNA extracted from FFPE tissues and 
2) it is possible to find a prognostic gene expression profile using a reduced number of genes.

\section{Methods}

\section{Patients and clinical data}

Case selection was performed retrospectively. To be included in the study, patients had to have stage I or II (TNM classification, 2002) estrogen and/or progesterone receptor-positive invasive ductal breast cancer. Patients also had to have tissue samples available for gene expression analysis, and were required to have received appropriate therapy (according to standard protocols) during the inclusion period. Appropriate therapy was defined as either mastectomy or tumorectomy plus adjuvant radiotherapy, as well as adjuvant hormonal therapy for 5 years in all patients and adjuvant anthracycline-based chemotherapy in N+ or in N0 patients with poor prognostic features. A minimum follow-up of 5 years was also required for all patients who did not relapse. Institutional approval from our ethics committee was obtained before the study was initiated.

\section{RNA isolation and CDNA synthesis}

The biological specimens used in this study were FFPE samples stored at the Pathology Department of our institution. An experienced pathologist evaluated H\&E preparations to select samples containing at least $70 \%$ tumor cells. Fifteen 5- $\mu \mathrm{m}$ sections from each FFPE sample were de-paraffinized with xylene and washed with ethanol. RNA was then extracted with the Master Pure ${ }^{\text {Tt }}$ Kit (Epicentre). We normalized to total RNA input; therefore, first-strand cDNA was synthesized from $1 \mu \mathrm{g}$ of total RNA using random primers, according to the High Capacity cDNA Reverse Transcription Kit protocol (Applied Biosystems).

\section{Quantitative RT-PCR}

qRT-PCR amplifications were performed with TaqMan Gene Expression Assay products in an ABI PRISM 7900 HT Sequence Detection System (Applied Biosystems). The reactions were carried out using TaqMan Low Density Arrays (TLDAs, Applied Biosystems). TLDAs have proved appropriate for assessment of FFPE samples [7]. For quality control, samples with insufficient tumor tissue, insufficient RNA (less than $1 \mu \mathrm{g}$ ), or a weak RT-PCR signal (average cycle threshold for the reference genes greater than 35) were excluded. A preliminary analysis was performed to compare gene expression measurements between paired FF and FFPE samples. The mean coefficient of variation for the same assays performed on different days or in different batches was less than $3 \%$.

\section{Gene selection}

We configured a TLDA series to analyze the genes included in the 70-Gene Signature[8], the Recurrence
Score [3] and the Two-Gene Ratio[9] with available TaqMan Gene Expression Assays (Supplementary table 1).

\section{Calculation of gene expression}

Average cycling threshold $(\mathrm{Ct})$ values[10], were obtained using SDS 2.2 software (Applied Biosystems). The maximum $\mathrm{Ct}$ value was set at 40 . Ct values were normalized using four housekeeping genes (IPO8, HMBS, POLR2A and SDHA). The relative expression level of each target gene was expressed as $\Delta \mathrm{Ct}=\mathrm{Ct}_{\mathrm{ref}}-\mathrm{Ct}_{\text {gene }}[11]$. Referencenormalized expression measurements were adjusted by defining the lowest expression value as 0 , with subse-

\section{Table 1: Clinical characteristics of the included patients*}

Median age: 58 years, range 29-82

Number of patients (\%)

$\mathrm{T}$

$1 \quad 77(50.3 \%)$

2

$76(49.7 \%)$

$\mathrm{N}$

$0 \quad 96(62.7 \%)$

$1 \quad 57(37.3 \%)$

\begin{tabular}{lc}
\hline Hormone receptor status & \\
ER+/PgR- & $30(19.6 \%)$ \\
ER+/PgR+ & $110(71.9 \%)$ \\
ER+/PgR unknown & $12(7.9 \%)$ \\
ER-/PgR+ & $1(0.7 \%)$ \\
\hline Grade & \\
1 & $29(18.9 \%)$ \\
2 & $64(41.8 \%)$ \\
3 & $59(38.6 \%)$ \\
Unknown & $1(0.7 \%)$ \\
\hline Chemotherapy & \\
No chemotherapy & $56(36.6 \%)$ \\
CMF & $42(27.4 \%)$ \\
\hline Anthracycline-based & $55(35.9 \%)$ \\
\hline
\end{tabular}

* All patients received adjuvant tamoxifen.

CMF: cyclophosphamide, methotrexate, 5-fluorouracil 
quent 1-unit increases reflecting an approximate doubling of the RNA [3].

\section{Methodology used to find a reduced profile}

First, genes displaying poor correlation in gene expression levels between fresh frozen and FFPE samples were discarded, as described elsewhere [12]. We computed a statistical significance level for each gene based on a univariate proportional hazards model [13] with the aim of identifying genes whose expression was significantly related to the distant metastasis-free survival (DMFS). Genes related to DMFS were subsequently filtered based on their $\mathrm{p}$-values $(\mathrm{p}<0.005)$ and the correlation between them. We then selected genes with the lowest p-values in each correlation group [3]). These selected genes were used to develop a gene expression-based prediction model of recurrence risk using the supervised principal component method of E. Bair and R. Tibshirani [14]. Leave-one-out cross-validation was used to evaluate the predictive accuracy of the profile. It was also used for initial screening of the genes. The cutoff point was established prior to gene selection including all samples. We assessed cutoff points leaving from $10 \%$ to $90 \%$ of patients in the low risk group and increasing by $10 \%$ each time. To test the statistical significance of each cutoff point, the p-value of the log-rank test statistic for the risk groups was evaluated using 1000 random permutations. Analyses were performed in BRB-ArrayTools v3.6.1 developed by R. Simon and A. Peng. We used the REMARK guidelines to ensure that the manuscript provided relevant information [15]. Additional description of the methods can be found in supplemental PDF file (Additional file 1, Additional methods).

\section{Statistical analyses}

To evaluate the prognostic value of the reduced gene score in our patient population, survival curves were estimated using Kaplan-Meier analysis and compared using the log-rank test. Univariate and multivariate Cox proportional-hazards analyses were also employed to create a final model that included the tumor grade (1 vs. 2 and 1 vs. 3 ), size ( $\leq 2 \mathrm{~cm}$ vs. $>2 \mathrm{~cm}$ ) and nodal status ( 0 vs. 1-3 positive nodes). Like other studies examining gene profiles in breast cancer, DMFS was the primary end point.

Two-way contingency-table analyses, as well as calculations of Cramer's V statistic, were also performed to measure the strength of the association between the 8-Gene Score (the score we identified) and the 70-Gene Signature and the Recurrence Score[16]. To assess model accuracy at five years, Harrell's bias-corrected concordance index was calculated. Models were refit 500 times using the bootstrap resampling technique. The concordance index is the percentage of patient pairs in which the predicted and observed outcomes coincide, such that $\mathrm{c}=0.5$ repre- sents agreement by chance and $\mathrm{c}=1.0$ represents perfect discrimination[17]. Concordance is identical to the area under a receiver operating characteristic curve (ROC)[18].

To define the continuous relationship between the 8gene Score and the 5-year DMFS rate, Gray's piecewiseconstant time-varying coefficients model was used[19]. A linear tail-restricted cubic spline function was generated using " $R$ " v 2.4.1 with the Design software package v2.012.

\section{Independent data sets}

Four independent databases that are available online were used as validation sets: 1) NKI [8], downloaded from the Rosetta Inpharmatics Web page http://www.rii.com/publications/2002/nejm.html, 2) SWE (GSE1456) [20], 3) UPP (GSE4922)[21], and 4) LOI (GSE6532) [22], downloaded from the NCBI GEO data repository http:// www.ncbi.nlm.nih.gov/projects/geo/index.cgi. To apply our qRT-PCR reduced gene score to these microarray data sets, the expression values of each set were $\mathrm{z}$-score transformed [23]. Expression values were adjusted, with the lowest expression value defined as 0 and other values scaled accordingly. Per-gene normalization within the validation cohorts was performed using median values obtained in the discovery cohort [24]. Survival curves were then estimated.

SPSS v9.1 software package and "R" v 2.4.1 (with the Design software package v2.0-12) were used for all statistical analyses. All $P$ values were two-sided, and $P<0.05$ was considered statistically significant.

\section{Results}

We considered 736 patients for inclusion in the study and a total of 153 patients were finally included. Additional file 2 Table S1 includes raw data of gene expression, whereas Additional file 3 Table S2 checks the REMARK recommendations along the manuscript. Table 1 describes the clinical features of and therapies received by the 153 patients. The median age was 58 years and the median follow-up was 91 months. Thirty-four patients (22\%) had a distant relapse, of whom 17 died and 7 were lost to follow-up after the relapse. Among 119 patients who did not have a distant relapse, four had a local/ regional recurrence that was successfully treated with surgery.

We first selected 53 genes that exhibited highly correlated expression levels in FF and FFPE samples. Seventeen genes were subsequently filtered based on their $P$ values related to DMFS. A model was built using these 17 genes (data not shown). Models with 10, 8, 7 or even fewer genes also demonstrated a good separation between groups at a low and high risk of distant recurrence. We selected a score based on 8 genes because it 
demonstrated the best performance. The 8-gene Score was calculated for each sample using reference-normalized expression measurements based on the following equation:

8-gene Score $=0.1936^{\circ} D T L+0.2176^{*} E C T 2+$ $0.0454^{*} \mathrm{MTDH}+0.1329 * \mathrm{PRC1}+0.0556^{*} \mathrm{RFC4}-$ $0.1913 *$ "SCUBE2 - 0.0443*STK32B - 0.1182"ZNF533.

Table 2 displays the names and coefficients of these 8 genes. Increased expression levels of DTL, ECT2, MTDH, PRC1 and RFC4 were associated with shorter disease-free survival, whereas increased expression levels of SCUBE2, STK32B, and ZNF533 were associated with longer disease-free survival. All of these genes are included in the 70-Gene Signature, although SCUBE2 is also included in the Recurrence Score.

BRB ArrayTools was used to define a cutoff point for risk stratification. We assessed cut-off points leaving from $10 \%$ to $90 \%$ of patients in the low risk group increasing by $10 \%$ each time. Best performance was obtained when $60 \%$ of the patients were allocated to the low-risk group. Patients with a total score $<2.86$ were assigned to the low risk of recurrence group and patients with a score $\geq 2.86$ constituted the high risk of recurrence group. The $P$-value of the log-rank test used to calculate recurrence risk between risk groups based on 1000 permutations was 0.018 .

DMFS at five years was $97.7 \%$ for patients in the lowrisk group and $60.6 \%$ for patients in the high-risk group (HR: 20.4, CI 95\%: 6.2 - 67.5; p < 0.001) (Figure 1A). DMFS at five years decreased continuously as the 8-Gene Score increased (Figure 2). Overall survival at five years was also calculated, and was found to be $98.9 \%$ for the low-risk group and $86.6 \%$ for the high-risk group (HR:
7.496, CI 95\%: $2.4-23.4 ; \mathrm{p}<0.001$ ). A univariate analysis evaluating the effects of pathological factors on DMFS and OS is presented in Additional file 4 Table S3.

A sub-analysis was performed to evaluate the influence of lymph node status on DMFS (Figures 1B and 1C). In patients with lymph node involvement, the 8-gene Score included half of each group (low- vs. high-risk), and DMFS at five years was $93.3 \%$ vs. $39.5 \%$, respectively. In women without lymph node involvement, the five-year DMFS rates were $100 \%$ vs. $75.7 \%$, respectively. We also evaluated the performance in the population of patients receiving just endocrine therapy and no chemotherapy (figure 1D).

The multivariate Cox proportional hazards analysis included the 8-gene Score, tumor size, nodal status and tumor grade. The 8-gene Score was able to predict DMFS (Table 3), indicating that this gene expression profile added important prognostic information beyond that provided by clinical factors. Lymph node status remained the only clinical factor with significant independent predictive value.

We used Cramer's V statistic to asses the concordance between other gene profiles $[3,4]$ and the 8-gene Score. The correlation between the 8-gene Score and the 70Gene Signature was 0.65 and the correlation was 0.58 for the Recurrence Score and 0.30 for the Two-Gene Index. These results indicate that there is a strong correlation between the 8-gene Score and both the 70-Gene Signature and the Recurrence Score. To assess the discriminative capability of each prognostic profile at five years, Harrell's bias-corrected concordance index was calculated. The calculated values were as follows: 8-gene Score

Table 2: Identification of the genes included in the 8-Gene Score

\begin{tabular}{|c|c|c|c|c|}
\hline Gene & p-value & Score coefficient & RefSeq & Assay ID \\
\hline DTL & $1.2 \mathrm{e}-06$ & 0.1936 & NM_016448.2 & Hs00212788_m1 \\
\hline $\mathrm{ECT} 2$ & $2.8 \mathrm{e}-06$ & 0.2176 & NM_018098.4 & Hs00216455_m1 \\
\hline MTDH & $2.9 e-06$ & 0.0454 & NM_178812.2 & Hs00757841_m1 \\
\hline PRC1 & $<1 \mathrm{e}-07$ & 0.1329 & NM_003981.2 & Hs00187740_m1 \\
\hline RFC4 & 0.0002592 & 0.0556 & NM_181573.2 & Hs00427469_m1 \\
\hline SCUBE2 & 0.0005634 & -0.1913 & NM_020974.1 & Hs00221277_m1 \\
\hline STK32B & 0.0004406 & -0.0443 & NM_018401.1 & Hs00179683_m1 \\
\hline ZNF533 & $2.13 e-05$ & -0.1182 & NM_152520.4 & Hs00332216_m1 \\
\hline
\end{tabular}




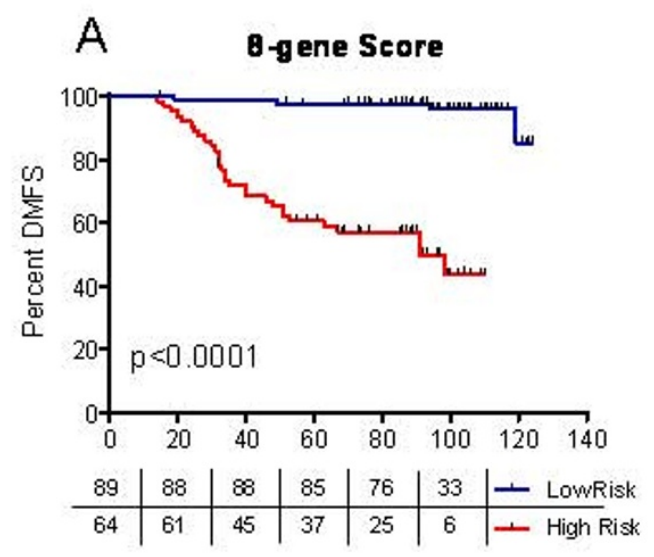

B

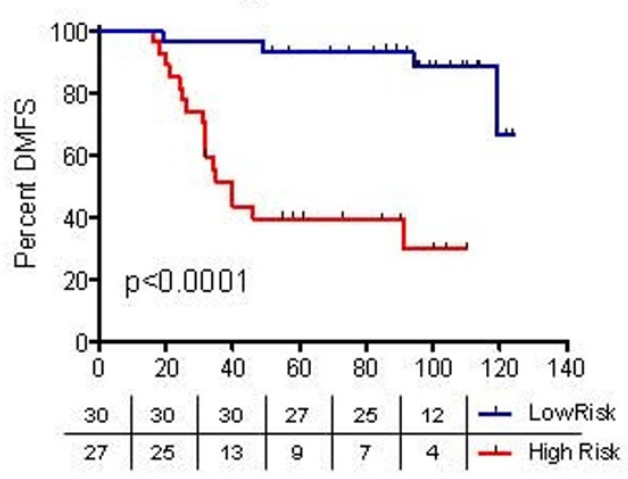

C 8-gene Seore N-

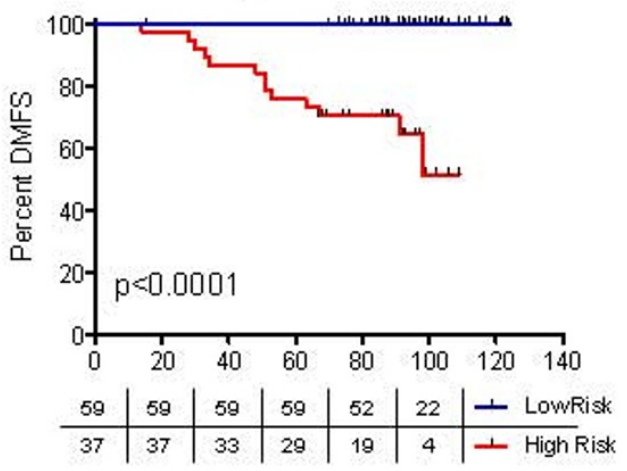

D 8-gene Se ore no Chem otherapy

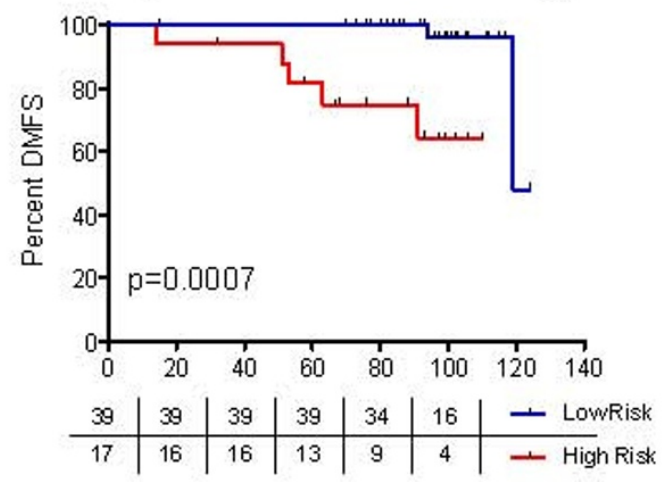

Figure 1 Kaplan-Meier curves showing distant metastasis-free survival (DMFS) for low-risk and high-risk patient groups (as defined by the 8-gene Score). A: all 153 patients included in this study B: patients with positive lymph nodes C: patients with negative lymph nodes D: patients who did not receive chemotherapy

$=0.81$, Recurrence Score $=0.73,70$-Gene Signature $=$ 0.70 , and Two-Gene Index $=0.59$.

We then applied the 8-gene Score to an online database from the Dutch Cancer Institute (NKI) that has been previously used to compare several gene profiles[16]. The 8- gene Score identified significant differences in DMFS for the entire group of 295 patients (Figure 3), as well as for the $\mathrm{N}+, \mathrm{N}-$, and ER + subgroups based on their score (Additional file 5 table S4). In comparison with the 70Gene Signature, the 8-gene Score categorized more 


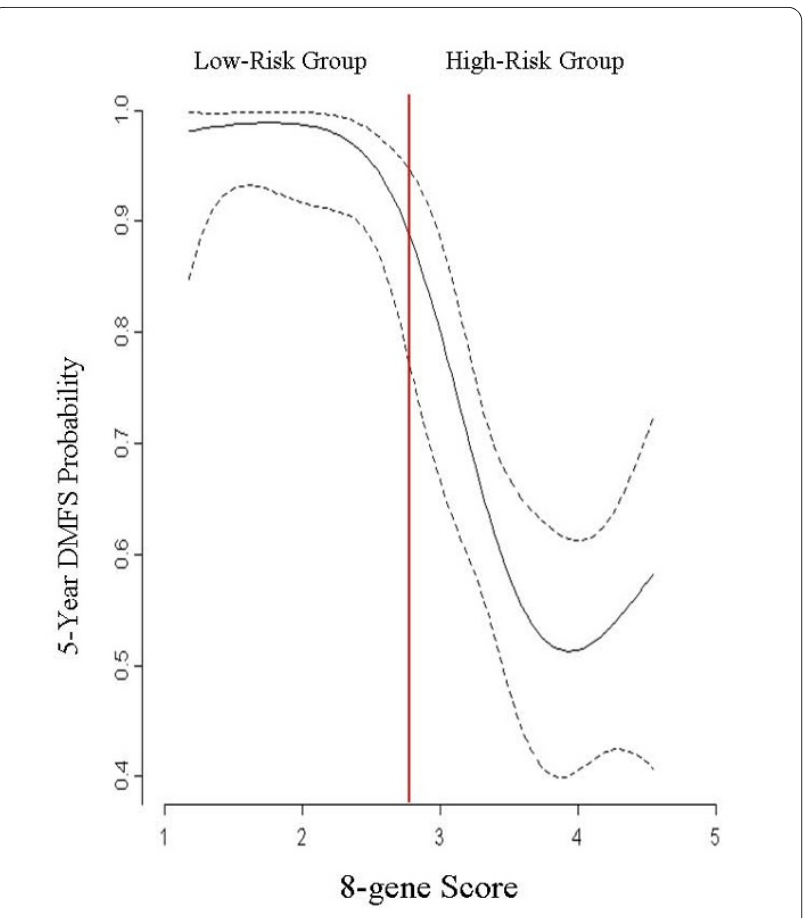

Figure 2 Distant metastasis-free survival (DMFS) rates as a continuous function of the 8-gene Score. The red line indicates the cutoff point. Dashed lines indicate the 95\% confidence interval.

patients as being low-risk, and DMFS was a bit lower for all groups. However, if the cutoff value was modified to include the same number of patients in the low-risk category as in the 70-Gene Signature, then the results for DMFS were virtually identical.

We subsequently analyzed the performance of the 8gene Score in three additional data sets: SWE (GSE1456)[20], UPP (GSE4922)[21], and LOI (GSE6532)[22]. Although the use of other external databases does not constitute a formal validation, it may provide insight about the performance of the gene set. A similar approach has recently been reported in bladder carcinoma [25]. In all data sets, the 8-Gene Score was able to identify significant differences in DMFS (figure 3). In all cases, the 8 -gene Score assigned more than $55 \%$ of the patients to the low-risk group. It predicted a DMFS rate of $>90 \%$ in the LOI and SWE data sets, and $>80 \%$ in the UPP data set.

\section{Discussion}

In the present study, we propose a qRT-PCR-derived prognostic score based on the expression levels of eight genes (the 8-Gene Score) for use in women with early breast cancer. The score can be determined using FFPE samples. It identified patients at high risk of recurrence in our series of patients as well as in four independent databases available online.
In comparison with women included in the other online databases, all of our patients received tamoxifen and two thirds were also treated with chemotherapy. The fact that the 8-gene Score worked well in these databases reflects its strength as a prognostic tool that can be used in large populations. Our gene expression profile was developed using hormonal receptor-positive tumors and, although it was derived from a signature validated in both positive and negative tumors [4], it should not be used for women with hormone receptor-negative tumors.

The genes included in the 8-gene Score are also part of the 70-Gene Signature, but the former should not be considered a scaled down version of the latter, because the 8Gene Score is applicable to FFPE samples and can be obtained using commercially available probes. Models with fewer than 8 genes performed similarly to the 8-gene Score, but the 8-gene Score was finally selected because it was more stable than smaller models and, at the same time, did not contain redundant information.

DTL, ECT2, MTDH, PRC1 and RFC4 have all been previously implicated in breast cancer; SCUBE2 and STK32B deletions have been found to be related to mental deficits in humans; and ZNF533 has been found to be associated with the Hedgehog signaling pathway in Zebrafish [26$35]$. Of note, MTDH activation by $8 \mathrm{q} 22$ genomic gain promotes chemoresistance and metastasis of poor-prognosis breast cancer [36]. The eight genes themselves could play an important role in the prognosis of breast cancer. Alternatively, their expression levels could vary in response to changes in the expression of more influential genes. This means that rather than identifying the ultimate genetic cause of a cancer, gene expression profiles may instead provide information about the molecular consequences of critical mutations. In our population, the 8-gene Score identified groups of patients whose DMFS rates differed, both in the whole patient population and in the node positive and node negative subgroups (figure 1). A sub-analysis of patients receiving endocrine therapy and no chemotherapy showed the possible relevance of the 8-gene profile for decision of chemotherapy.

According to the results from the NKI series [16], the 8gene Score performed as well as the 70-Gene Signature (Additional file 5 table S4). The DMFS and OS rate values were higher using the 70-Gene Signature, probably due to the different number of patients assigned to low- versus high-risk groups in each profile, as well as to the fact that many women in the NKI series did not receive adjuvant therapy [37]

The 8-gene Score did not perform as well in other data sets as it did in ours, probably because of substantial differences in the use of adjuvant therapy. For instance, many women with estrogen receptor-positive tumors did not receive adjuvant hormonal therapy in the UPP series, 
Table 3: Multivariate analysis of factors associated with distant metastasis-free survival in the 8-gene Score, the 70-Gene Signature and the Recurrence Score

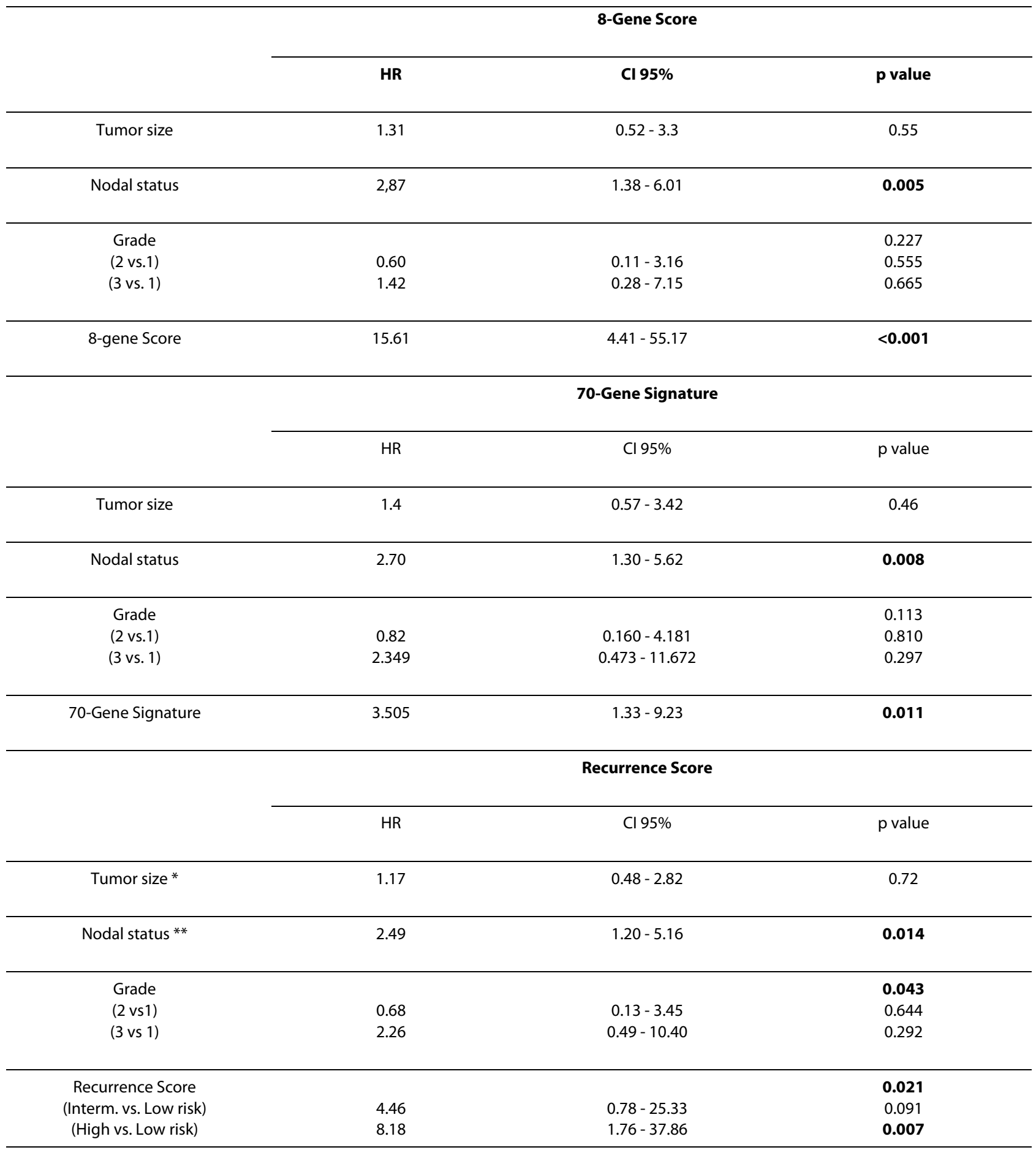

*Tumor size: $>2 \mathrm{~cm}$ vs. $\leq 2 \mathrm{~cm} .{ }^{* *}$ Nodal status: positive (1-3) vs negative. 

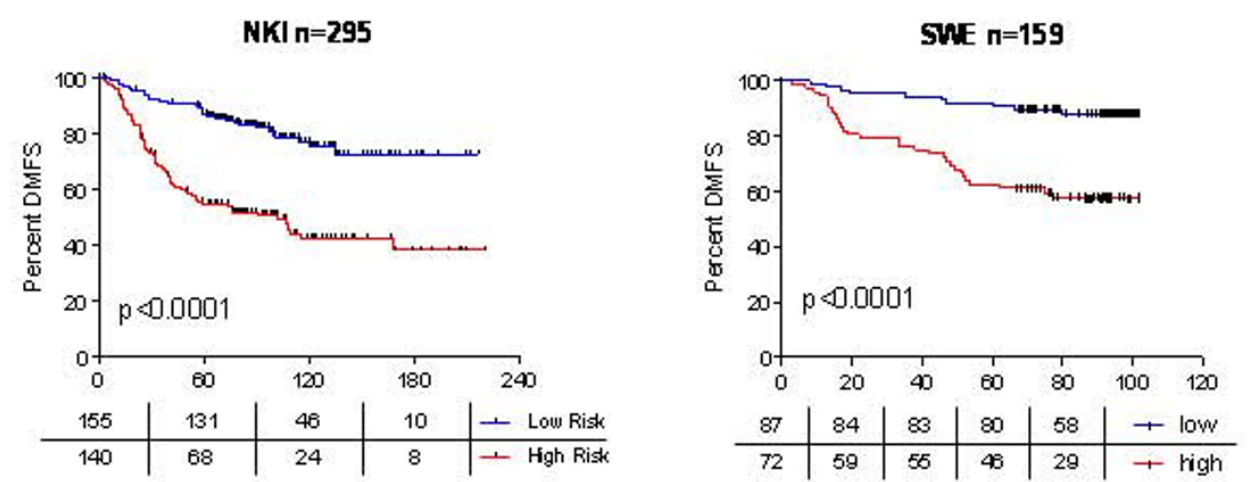

LOI $n=380$

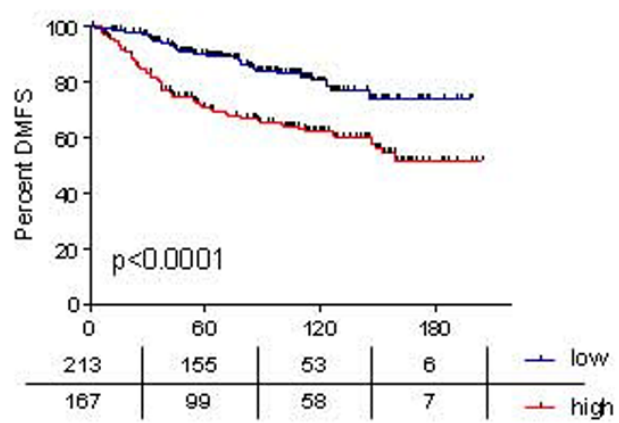

UPP $n=249$

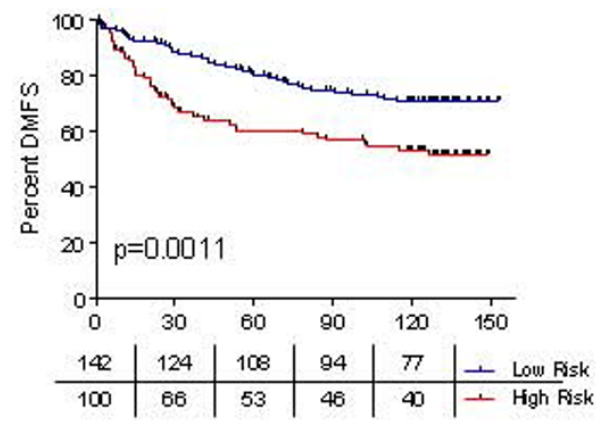

Figure 3 Kaplan-Meier curves showing distant metastasis-free survival (DMFS) for patients included in four databases available online

and most did not even receive chemotherapy although over one third of these patients had positive lymph nodes[21]. The series by Loi et al. included women with hormone receptor-positive tumors who were treated with tamoxifen, but chemotherapy was not used in any patient [22]. Our profile was generated in a population of women who had a very good prognosis and received optimal adjuvant therapy, and therefore the cutoff values identified using this cohort may be a bit too optimistic for "suboptimally" treated populations. This suggests that the 8gene Score may provide not only prognostic but also predictive information. However, because our profile works as a continuous variable, the cutoff value can be changed to become less restrictive depending on the patient group to which it is applied.
Our study has some limitations. Whereas the 70-Gene Signature and the Recurrence Score have undergone extensive investigation and clinical use, the 8-gene Score is still undergoing initial development. Our retrospective series included a limited number of patients and the treatment they received was not uniform. Furthermore, without an independent validation series, we cannot rule out overestimation of the prognostic value of the 8-gene Score. The application of our score to external data sets may temper this limitation, but it is not a formal validation. Without such validation, the score cannot facilitate treatment choices, as it neither distinguishes between therapy benefit nor identifies a group of patients that do not need any therapy. The use of different populations in the discovery phase may certainly yield different profiles, but our point was to demonstrate that a small subset of 
informative genes could provide a significantly prognostic score.

The 8-gene Score correlated very well with two currently available gene profiles: the 70-Gene Signature and the Recurrence Score. The discrimination capacity (Harrell's $C$ index) was high for all three profiles. The TwoGene Index did not perform similarly to the 8-Gene Score in our cohort of patients, but this does not demonstrate inferiority. On the other hand, the performance of this index has recently been improved with the incorporation of five additional genes related to the tumor grade [38].

We feel that the 8-gene Score has three main advantages. First, it can be used in FFPE samples with commercial probes. Second, considering the modular nature of this platform, it would be easy and inexpensive to add further genes that might provide additional information, as has been done with the Two-Gene Index [38]. Next generation profiles could include both prognostic and predictive information, for instance. Finally, qRT-PCR using TLDAs can be easily implemented in the clinical setting.

\section{Conclusions}

We have described an 8-gene prognostic Score that can be used in FFPE samples from patients with early hormone receptor-positive breast cancer. The main interest of this study is that it opens the door to the use of gene expression profiling based on small sets of genes in local laboratories.

\section{Competing interests and funding}

The 8-gene Score is under patent OEPM P-200803509 (December 2008), "Method for the sub-classification of tumours".

This work was supported by FIS Grant PI050668 (Instituto de Salud Carlos III, Ministerio de Sanidad y Consumo, Spain) (EE, ISN, JAFV), Fundación SEOM grant 2006 (EE), Red Temática de Investigación Cooperativa en Cáncer (RTICC, RD06-0020-1022), FEDER funds and unrestricted grants from Astra-Zeneca, Bristol-Myers Squibb, Cephalon-Pharma, Glaxo SmithKline, Roche Farma, Sanofi-Aventis and Schering-Plough.

JAFV is supported by FIS Grant CP05/00248 from Fondo de Investigación Sanitaria (Instituto de Salud Carlos III, Ministerio de Sanidad y Consumo, Spain).

AGP is the recipient of a fellowship from the Ministerio de Educación y Ciencia, Spain. ISN is supported by Fundación para la Investigación del Hospital Universitario La Paz.

\section{Additional material}

Additional file $\mathbf{1}$ additional methods. further description of methods used to determine cutoff point and to find a reduced gene profile.

Additional file $\mathbf{2}$ Table S1, Raw data. Table with list of genes included in the study, raw data of gene expression and clinical data

Additional file $\mathbf{3}$ Table S2, REMARK criteria. checking of REMARK criteria for marker development throughout text

Additional file 4 Table S3, univariate analysis. table displaying univariate analysis for distant metastasis-free survival and overall survival

Additional file 5 Table S4, DMFS in online databases. table displaying percentages of patients in low and high risk groups, as well as distant metastasis-free survival percentages in online available databases.

\section{Authors' contributions}

ISN, AGP and JAFV helped designing the study, carried out the molecular studies and drafted the manuscript. RM and BSJ performed the statistical analysis. DH performed the pathological workup. AP, PZ, AR, JF, PC and MGB contributed to the design of the study. RL contributed to the laboratory workup. EE conceived and designed the study the study and drafted the manuscript. All authors read and approved the final manuscript.

\section{Acknowledgements}

We thank Ricardo Ramos for his technical expertise in qRT-PCR analyses and Esther Díaz and María Miguel for their assistance in the handling and analysis of the tumor samples.

Preliminary data from this study were presented at the San Antonio Breast Cancer Symposium, December 2008.

\section{Author Details}

1 Unidad de Investigación, Instituto de Investigación Sanitaria IdIPAZ, Hospital Universitario La Paz (Paseo de la Castellana, 261), Madrid (28046), Spain, 2Service of Oncology, IdIPAZ, Hospital Universitario La Paz (Paseo de la Castellana, 261), Madrid (28046), Spain, 3Service of Pathology, IdIPAZ, Hospital Universitario La Paz (Paseo de la Castellana, 261), Madrid (28046), Spain, 4 Service of Statistics, IdIPAZ, Hospital Universitario La Paz (Paseo de la Castellana, 261), Madrid (28046), Spain and ${ }^{5}$ Chair of Oncology \& Palliative care, Facultad de Medicina, Universidad Autónoma de Madrid (Arzobispo Morcillo $n^{\circ} 2$ y 4), Madrid (28029), Spain

Received: 30 October 2009 Accepted: 28 June 2010

Published: 28 June 2010

References

1. Goldhirsch A, Wood WC, Gelber RD, Coates AS, Thurlimann B, Senn HJ: Progress and promise: highlights of the international expert consensus on the primary therapy of early breast cancer 2007. Ann Oncol 2007 , 18(7):1133-1144.

2. Olivotto IA, Bajdik CD, Ravdin PM, Speers CH, Coldman AJ, Norris BD, Davis GJ, Chia SK, Gelmon KA: Population-based validation of the prognostic model ADJUVANT! for early breast cancer. J Clin Oncol 2005 23(12):2716-2725.

3. Paik S, Shak S, Tang G, Kim C, Baker J, Cronin M, Baehner FL, Walker MG, Watson D, Park T, Hiller W, Fisher ER, Wickerham DL, Bryant J, Wolmark N: A multigene assay to predict recurrence of tamoxifen-treated, nodenegative breast cancer. N Engl J Med 2004, 351(27):2817-2826.

4. van de Vijver MJ, He YD, van't Veer LJ, Dai H, Hart AA, Voskuil DW, Schreiber GJ, Peterse JL, Roberts C, Marton MJ, Parrish M, Atsma D, Witteveen A, Glas A, Delahaye L, van der Velde T, Bartelink H, Rodenhuis S, Rutgers ET, Friend SH, Bernards R: A gene-expression signature as a predictor of survival in breast cancer. NEngl J Med 2002, 347(25):1999-2009.

5. Espinosa E, Sánchez-Navarro I, Gámez-Pozo A, al e: Comparison of Prognostic Gene Profiles Using qRT-PCR in Paraffin Samples: A Retrospective Study in Patients with Early Breast Cancer. PLOS ONE 2009, 4(6):e5911. 
6. Espinosa E, Vara JA, Redondo A, Sanchez JJ, Hardisson D, Zamora P, Pastrana FG, Cejas P, Martinez B, Suarez A, Calero F, Baron MG: Breast cancer prognosis determined by gene expression profiling: a quantitative reverse transcriptase polymerase chain reaction study. $J$ Clin Oncol 2005, 23(29):7278-7285.

7. Sanchez-Espiridion B, Sanchez-Aguilera A, Montalban C, Martin C, Martinez R, Gonzalez-Carrero J, Poderos C, Bellas C, Fresno MF, Morante C, Mestre MJ, Mendez M, Mazorra F, Conde E, Castano A, Sanchez-Godoy P, Tomas JF, Morente MM, Piris MA, Garcia JF: A TaqMan low-density array to predict outcome in advanced Hodgkin's lymphoma using paraffinembedded samples. Clin Cancer Res 2009, 15(4):1367-1375.

8. van 't Veer LJ, Dai H, van de Vijver MJ, He YD, Hart AA, Mao M, Peterse HL, van der Kooy K, Marton MJ, Witteveen AT, Schreiber GJ, Kerkhoven RM, Roberts C, Linsley PS, Bernards R, Friend SH: Gene expression profiling predicts clinical outcome of breast cancer. Nature 2002, 415(6871):530-536

9. Ma XJ, Hilsenbeck SG, Wang W, Ding L, Sgroi DC, Bender RA, Osborne CK, Allred DC, Erlander MG: The HOXB13:IL17BR expression index is a prognostic factor in early-stage breast cancer. $J$ Clin Oncol 2006, 24(28):4611-4619.

10. Pfaffl MW: A new mathematical model for relative quantification in realtime RT-PCR. Nucleic Acids Res 2001, 29(9):e45.

11. Livak KJ, Schmittgen TD: Analysis of relative gene expression data using real-time quantitative PCR and the 2(-Delta Delta $C(T)$ ) Method. Methods 2001, 25(4):402-408.

12. Sánchez-Navarro I, Gámez-Pozo A, González Barón M, Pinto A, Hardisson D, López R, Madero R, Cejas P, Mendiola M, Espinosa E, Fresno-Vara JA: Comparison of gene expression profiling by reverse transcription quantitative PCR between fresh frozen and formalin-fixed, paraffinembedded breast cancer tissues. Biotechniques 2010, 48(5):389-397.

13. Cox DR: Regression models and life-tables. J Roy Stat Soc 1972, 34:187-220.

14. Bair E, Tibshirani R: Semi-supervised methods to predict patient survival from gene expression data. PLOS Biol 2004, 2(4):E108.

15. McShane LM, Altman DG, Sauerbrei W, Taube SE, Gion M, Clark GM: Reporting recommendations for tumor marker prognostic studies (REMARK). J Nat/ Cancer Inst 2005, 97(16):1180-1184.

16. Fan C, Oh DS, Wessels L, Weigelt B, Nuyten DS, Nobel AB, van't Veer $L$, Perou CM: Concordance among gene-expression-based predictors for breast cancer. N Engl J Med 2006, 355(6):560-569.

17. Harrell FE Jr, Lee KL, Mark DB: Multivariable prognostic models: issues in developing models, evaluating assumptions and adequacy, and measuring and reducing errors. Stat Med 1996, 15(4):361-387.

18. Pencina MJ, D'Agostino RB: Overall $C$ as a measure of discrimination in survival analysis: model specific population value and confidence interval estimation. Stat Med 2004, 23(13):2109-2123.

19. Gray R: Flexible methods for analyzing survival data using splines, with applications to breast cancer prognosis. J Am Stat Assoc 1992, 87:942-951.

20. Pawitan Y, Bjohle J, Amler L, Borg AL, Egyhazi S, Hall P, Han X, Holmberg L, Huang F, Klaar S, Liu ET, Miller L, Nordgren H, Ploner A, Sandelin K, Shaw PM, Smeds J, Skoog L, Wedren S, Bergh J: Gene expression profiling spares early breast cancer patients from adjuvant therapy: derived and validated in two population-based cohorts. Breast Cancer Res 2005, 7(6):R953-964.

21. Ivshina AV, George J, Senko O, Mow B, Putti TC, Smeds J, Lindahl T, Pawitan Y, Hall P, Nordgren H, Wong JE, Liu ET, Bergh J, Kuznetsov VA, Miller LD: Genetic reclassification of histologic grade delineates new clinical subtypes of breast cancer. Cancer Res 2006, 66(21):10292-10301.

22. Loi S, Haibe-Kains B, Desmedt C, Wirapati P, Lallemand F, Tutt AM, Gillet C, Ellis P, Ryder K, Reid JF, Daidone MG, Pierotti MA, Berns EM, Jansen MP, Foekens JA, Delorenzi M, Bontempi G, Piccart MJ, Sotiriou C: Predicting prognosis using molecular profiling in estrogen receptor-positive breast cancer treated with tamoxifen. BMC Genomics 2008, 9:239.

23. Cheadle C, Vawter MP, Freed WJ, Becker KG: Analysis of microarray data using Z score transformation. J Mol Diagn 2003, 5(2):73-81.

24. Schmidt M, Bohm D, von Torne C, Steiner E, Puhl A, Pilch H, Lehr HA, Hengstler JG, Kolbl H, Gehrmann M: The humoral immune system has a key prognostic impact in node-negative breast cancer. Cancer Res 2008, 68(13):5405-5413.

25. Mitra AP, Pagliarulo V, Yang D, Waldman FM, Datar RH, Skinner DG, Groshen S, Cote RJ: Generation of a concise gene panel for outcome prediction in urinary bladder cancer. $J$ Clin Oncol 2009, 27(24):3929-3937.

26. Arai M, Kondoh N, Imazeki N, Hada A, Hatsuse K, Matsubara O, Yamamoto $\mathrm{M}$ : The knockdown of endogenous replication factor $\mathrm{C} 4$ decreases the growth and enhances the chemosensitivity of hepatocellular carcinoma cells. Liver Int 2008

27. Chaib H, Cockrell EK, Rubin MA, Macoska JA: Profiling and verification of gene expression patterns in normal and malignant human prostate tissues by cDNA microarray analysis. Neoplasia 2001, 3(1):43-52.

28. Hollway GE, Maule J, Gautier P, Evans TM, Keenan DG, Lohs C, Fischer D, Wicking C, Currie PD: Scube2 mediates Hedgehog signalling in the zebrafish embryo. Dev Biol 2006, 294(1):104-118.

29. Li J, Zhang N, Song LB, Liao WT, Jiang LL, Gong LY, Wu J, Yuan J, Zhang HZ, Zeng MS, Li M: Astrocyte elevated gene-1 is a novel prognostic marker for breast cancer progression and overall patient survival. Clin Cancer Res 2008, 14(11):3319-3326.

30. Monfort S, Rosello M, Orellana C, Oltra S, Blesa D, Kok K, Ferrer I, Cigudosa $J C$, Martinez F: Detection of known and novel genomic rearrangements by array based comparative genomic hybridisation: deletion of ZNF533 and duplication of CHARGE syndrome genes. J Med Genet 2008, 45(7):432-437

31. Namba R, Maglione JE, Young LJ, Borowsky AD, Cardiff RD, MacLeod CL, Gregg JP: Molecular characterization of the transition to malignancy in a genetically engineered mouse-based model of ductal carcinoma in situ. Mol Cancer Res 2004, 2(8):453-463.

32. Narayan G, Bourdon V, Chaganti S, Arias-Pulido H, Nandula SV, Rao PH, Gissmann L, Durst M, Schneider A, Pothuri B, Mansukhani M, Basso K Chaganti RS, Murty V: Gene dosage alterations revealed by cDNA microarray analysis in cervical cancer: identification of candidate amplified and overexpressed genes. Genes Chromosomes Cancer 2007, 46(4):373-384.

33. Slebos RJ, Yi Y, Ely K, Carter J, Evjen A, Zhang X, Shyr Y, Murphy BM, Cmelak AJ, Burkey BB, Netterville JL, Levy S, Yarbrough WG, Chung CH: Gene expression differences associated with human papillomavirus status in head and neck squamous cell carcinoma. Clin Cancer Res 2006, 12(3 Pt 1):701-709.

34. Temtamy SA, Aglan MS, Valencia M, Cocchi G, Pacheco M, Ashour AM, Amr KS, Helmy SM, El-Gammal MA, Wright M, Lapunzina P, Goodship JA, RuizPerez VL: Long interspersed nuclear element-1 (LINE1)-mediated deletion of EVC, EVC2, C4orf6, and STK32B in Ellis-van Creveld syndrome with borderline intelligence. Hum Mutat 2008, 29(7):931-938.

35. Ueki T, Nishidate T, Park JH, Lin ML, Shimo A, Hirata K, Nakamura Y, Katagiri T: Involvement of elevated expression of multiple cell-cycle regulator, DTL/RAMP (denticleless/RA-regulated nuclear matrix associated protein), in the growth of breast cancer cells. Oncogene 2008.

36. Hu G, Chong RA, Yang Q, Wei Y, Blanco MA, Li F, Reiss M, Au JL, Haffty BG, Kang Y: MTDH activation by $8 q 22$ genomic gain promotes chemoresistance and metastasis of poor-prognosis breast cancer. Cancer Cell 2009, 15(1):9-20.

37. Koscielny S: Critical review of microarray-based prognostic tests and trials in breast cancer. Curr Opin Obstet Gynecol 2008, 20(1):47-50.

38. Ma XJ, Salunga R, Dahiya S, Wang W, Carney E, Durbecq V, Harris A, Goss P, Sotiriou C, Erlander M, Sgroi D: A five-gene molecular grade index and HOXB13:IL17BR are complementary prognostic factors in early stage breast cancer. Clin Cancer Res 2008, 14(9):2601-2608.

Pre-publication history

The pre-publication history for this paper can be accessed here: http://www.biomedcentral.com/1471-2407/10/336/prepub

\section{doi: $10.1186 / 1471-2407-10-336$}

Cite this article as: Sánchez-Navarro et al., An 8-gene qRT-PCR-based gene expression score that has prognostic value in early breast cancer BMC Cancer 2010, 10:336 